\title{
Intraguild predation reduces bacterial species richness and loosens the viral loop in aquatic systems: 'kill the killer of the winner' hypothesis
}

\author{
Takeshi Miki*, Norio Yamamura \\ Center for Ecological Research, Kyoto University, Hiranocho 2-509-3, Otsu, Shiga 520-2113, Japan
}

\begin{abstract}
Viruses perform an ecological function (diversity regulation) and a biogeochemical function (viral loop) in microbial food webs. We used an idealized food web model to evaluate the impact of viral loss by protozoan grazing on these 2 functions. Viral loss by protozoan grazing is an example of intraguild predation (IGP); protozoan predators kill viruses, which in turn kill the winner of the nutrient competition among bacteria. The model considers the interactions among uninfected and infected host cells, free-living viruses, protozoa, and nutrients. Calculations showed that this 'kill the killer of the winner' (KKW) process has a negative effect on bacterial species richness (BSR). This is because the KKW process reduces the virus to bacteria ratio, which undermines the 'kill the winner' (KW) process. In particular, the intensity of the KKW process is influenced by the latent period of viruses; a longer latent period leads to a reduction in BSR by causing the viruses in host cells to be more at risk of being killed by grazing. In addition, under high IGP with a long latent period, eutrophication leads to a decrease in the virus to protozoa ratio, resulting in a lower BSR and a smaller contribution of the virus loop to nutrient cycling, whereas the changes are minimal under low IGP with a short latent period.
\end{abstract}

KEY WORDS: Bacterial diversity $\cdot$ Kill the winner $\cdot$ Microbial food webs $\cdot$ Theoretical model Resale or republication not permitted without written consent of the publisher

\section{INTRODUCTION}

Viruses and bacteria are the most abundant microorganisms in aquatic ecosystems, with abundances typically on the order of $10^{10}$ and $10^{9} \mathrm{l}^{-1}$, respectively (Noble \& Fuhrman 1998). Therefore, interactions between bacteria and viruses are one of the most important trophic links in aquatic microbial food webs, not only as a maintenance mechanism of high bacterial diversity, as proposed in the 'kill the winner' (KW) hypothesis by Thingstad \& Lignell (1997), but also with regard to the 'viral loop' (Bratbak et al. 1992), which diminishes material flow from bacteria to higher trophic levels (Fuhrman 1999). In the KW hypothesis, viruses with high host specificity serve as the mechanism that more frequently 'kills' hosts with higher growth rates (the 'winner' of the competition for nutrients), preventing competitive exclusion and thus main- taining bacterial species richness (BSR). In contrast, protozoan predators with non-selective grazing limit only the total abundance of bacteria in the community (Thingstad \& Lignell 1997). Many observations and experiments support this hypothesis, suggesting that bacterial community composition (Fuhrman \& Schwalbach 2003, Schwalbach et al. 2004, Winter et al. 2004) and species richness (Hewson et al. 2003) are influenced by the abundance of viruses. Furthermore, Thingstad (2000) developed a theory using a simple microbial food web model based on the KW hypothesis and reproduced the observed patterns in structure and nutrient cycling in microbial food webs, e.g. a 1:10 ratio of bacterial to viral abundance and losses of 10 to $50 \%$ of bacterial production into the viral loop.

However, new evidence suggests that ecological (KW) and biogeochemical (viral loop) functions of viruses may be counterbalanced by an additional 


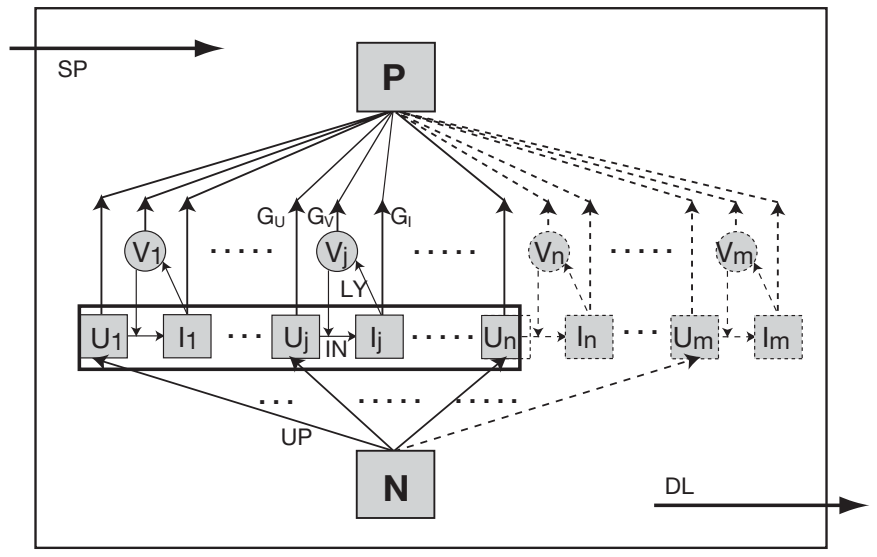

Fig. 1. Chemostat model of an idealized food web. $N$ : nutrients available for bacteria; $U_{j}$ : uninfected cells of bacterial species $j_{i}$ $I_{j}$ : infected cells of bacterial species $j_{i} V_{j}$ : free-living viruses whose host is bacterial species $j_{i} P$ : protozoa. Each process shown is as follows; UP: uptake of nutrients; IN: incidence process between uninfected cells and free-living viruses; LY: viral lysis; $G_{U}$ : grazing on uninfected bacteria; $G_{V}$ : grazing on free-living viruses (omnivorous intraguild predation [IGP]); $\mathrm{G}_{\mathrm{I}}$ : grazing on infected bacteria (coincidental IGP); SP: supply of nutrient, and immigration of bacteria, viruses, and protozoa; and DL: dilution of nutrient, bacteria, viruses, and protozoa. The set of $m$ bacterial species and $m$ viral species, and protozoa is assumed to be the metacommunity. For each bacterial species $j$, cells in the population are divided into 2 populations: uninfected $\left(U_{j}\right)$ and infected $\left(I_{j}\right)$. Viruses $(j>n-1)$ and hosts $(j>n)$ are competitively excluded from the system, as indicated by the dashed lines, if there is no immigration of bacteria, viruses, and protozoa. Natural losses of viruses and protozoa and recycling processes are omitted for simplicity

trophic link within bacteria-virus-protozoa interactions. Several experiments have indicated that the viral loss rate is enhanced by the presence of protozoa (Suttle \& Chen 1992, González \& Suttle 1993, Manage et al. 2002), suggesting the existence of intraguild predation (IGP; see Holt \& Polis 1997) between protozoa and viruses. Viruses are killed by protozoa, either indirectly through grazing on infected host cells (coincidental IGP; Polis et al. 1989) or directly through grazing on free-living progeny (omnivorous IGP; Polis et al. 1989). These IGP processes, which we call 'kill the killer of the winner' (KKW), have the potential to reduce the abundance of the viruses that are the 'killer of the winner', resulting in a decreased viral infection rate. Nevertheless, few studies have explored its consequences for biodiversity, community structure, and biogeochemical cycling (González \& Suttle 1993, Fuhrman 1999), probably because the estimated intensity of direct grazing (omnivorous IGP) is relatively low (i.e. 2.6 to $4.8 \%$ of the grazing rate on bacterial cells; González \& Suttle 1993). In addition, the effects of coincidental IGP in these systems are not clear.
In this study, we focused on the KKW processes and on both coincidental and omnivorous IGP. Specifically, we hypothesized that by deteriorating the KW process, IGP reduces BSR, and that IGP reduces the contribution of the viral loop to nutrient cycling in the microbial loop. We validated this hypothesis by using an idealized food web model, which is an extension of the food web model based on the KW hypothesis (hereafter referred to as the KW food web model; Thingstad 2000). Our new assumptions are that there are 2 populations of bacteria (uninfected and infected cells) and that both free-living viruses and viruses with infected bacterial cells are grazed on by protozoa. Assuming the existence of uninfected and infected populations (Binder 1999, Malchow et al. 2004, Singh et al. 2004) is one of the natural generalizations of the KW food web model, which neglects the latent period of viruses, because a variable latent period has been observed (Middelboe 2000, Lee et al. 2004).

Using these additional assumptions, we evaluated BSR in response to grazing on infected bacterial cells (coincidental IGP) and free-living viruses (omnivorous IGP). We also examined how the latent period affects BSR through changes in the intensity of coincidental IGP and food web structures. Note that increasing the latent period makes it more likely that viruses in host cells are killed by protozoa. As food web structures, we focused on the virus to bacteria ratio, protozoa to bacteria ratio, and protozoa to virus ratio. Furthermore, we examined how environmental changes cause changes in food web structures and thus in BSR. We focused on the changes in top-down regulation in protozoa and in the trophic status that influences the resource availability for bacteria.

\section{METHODS}

Model. We considered a chemostat model, which is an open system with continuous inflow and outflow (Smith \& Waltman 1995). A constant dilution rate, $D$, (i.e. flow rate per system volume) was assumed. For trophic interactions among bacteria, viruses, and protozoa in the system, we adopted a type of idealized food web model (Fig. 1), based on the KW food web model by Thingstad (2000). The model system consists of a set of $m$ bacterial species, and 2 populations are assumed for each species: uninfected cells with a density $U_{j}(j=1, \ldots, m)$ and virus-infected cells with a density $I_{j}$. All uninfected cells of all species compete for a unique limiting nutrient with concentration $N$, whereas infected cells do not reproduce and do not consume any nutrients; our model deals only with lytic infection. For each bacterial species, there is a hostspecific virus with density $V_{j}$. We also assume 1 gener- 
alist protozoan predator with density $P$, which corresponds to an idealized 'heterotrophic flagellate' grazing non-selectively with the same attack rate on all bacterial species. Furthermore, as an open system, we assume not only the supply of nutrients into the system, but also the immigration of bacteria, viruses, and protozoa into the system from the metacommunity. This assumption is reasonable, because it has been suggested that these microorganisms generally have a large distribution and high dispersal ability (see Schlegel \& Jannasch 1981, Bianchi \& Bianchi 1995 for bacteria, and Fenchel et al. 1997, Hillebrand et al. 2001 for protozoa). For simplicity, we set a constant and common immigration rate $i_{M}$ for all microorganisms (bacteria, viruses, and protozoa). We next describe the dynamics of each component $\left(U_{j}, I_{j}, V_{j}, P, N\right)$ in the model using differential equations.

Uninfected cells of bacterial species $\boldsymbol{j}$ : Uninfected cells of species $j$ take up nutrients at rate $\alpha_{j} N$ per unit time per cell, where $\alpha_{j}$ is the species-specific affinity of the given nutrient. The growth rate is $Y_{B} \alpha_{j} \rho_{B}{ }^{-1} N$, where $\rho_{B}$ and $Y_{B}$ represent nutrient content per cell and growth efficiency, respectively. For illustrative purposes, we can arrange the bacterial species according to decreasing nutrient affinity $\left(\alpha_{1}>\alpha_{2}>\ldots>\alpha_{j}\right.$ $>\ldots>\alpha_{m}$ ). Thus, species 1 has the highest growth rate and is the best competitor for the nutrient. Uninfected cells are attacked by protozoa at a rate of $\alpha_{P U} P$ per cell, where $\alpha_{P U}$ is the grazing rate (clearance rate) on uninfected cells. In addition, we assume that the infection rate per cell is proportional to the density of free-living viruses $\left(\beta V_{j}\right)$ (Middelboe 2000). Thus, the equation for the dynamics is given by:

$$
\mathrm{d} U_{j} / \mathrm{d} t=i_{M}+Y_{B} \alpha_{j} \rho_{B}{ }^{-1} N U_{j}-\alpha_{P U} U_{j} P-\beta V_{j} U_{j}-D U_{j}
$$

where $i_{M}$ represents the immigration of cells into the system, and $D U_{j}$ the dilution of uninfected cells from the system.

Infected cells of bacterial species $\boldsymbol{j}$ : Infected cells of species $j$ increase along with infection processes at a rate of $\beta U_{j} V_{j}$ per unit time, and they do not reproduce because only lytic viral infection is considered. Infected cells are lost by viral lysis at a rate of $L^{-1}$ per unit time per cell. This is the simplest and standard assumption for the latent period in epidemic models (Anderson \& May 1992). $L$ represents the average duration of the latent period, hereafter simply referred to as the latent period (Middelboe 2000). We assume that infected bacterial cells are grazed on by protozoa at a rate of $\alpha_{\mathrm{PI}} P$. Note that this process represents coincidental IGP. The equation for the dynamics is given by:

$$
\mathrm{d} I_{j} / \mathrm{d} t=i_{M}+\beta U_{j} V_{j}-L^{-1} I_{j}-\alpha_{P I} I_{j} P-D I_{j}
$$

where $D I_{j}$ is the dilution of infected cells from the system.
Free-living virus $\boldsymbol{j}$ : We assume that 1 infected bacterial cell contains $n_{V}$ viral particles of species $j$. The nutrient content of the infected cell is $\rho_{B}+n_{V} \rho_{V i}$ we set the nutrient content per virus as $\rho_{V}$. For simplicity, we assume that viruses produce new viral particles by using the nutrient content of infected cells only, without forcing the bacterial host cell to take up additional nutrients. Therefore, burst size per lysis can be calculated as $Y_{V}\left(\rho_{B} \rho_{V}^{-1}+n_{V}\right)$, where $Y_{V}$ is the growth efficiency, and the production rate of progeny viruses is $Y_{V}\left(\rho_{B} \rho_{V}{ }^{-1}+\right.$ $\left.n_{V}\right) L^{-1} I_{j}$ per unit time. We assume 3 loss processes: viruse are lost by the attachment to uninfected cells at a rate of $n_{V} \beta U_{j}$ per virus, through natural decay at a constant rate of $\lambda$ per virus, or by grazing by protozoa at a rate of $\alpha_{P V} P$ per virus, representing omnivorous IGP. Thus, the equation for the dynamics is given by:

$$
\begin{aligned}
\mathrm{d} V_{j} / \mathrm{d} t= & i_{M}+Y_{V}\left(\rho_{B} \rho_{V}^{-1}+n_{V}\right) L^{-1} I_{j}- \\
& n_{V} \beta U_{j} V_{j}-\lambda V_{j}-\alpha_{P V} P V_{j}-D V_{j}
\end{aligned}
$$

where $D V_{j}$ is the dilution of free-living virus from the system.

Protozoa: We can calculate the growth rate of protozoa using nutrient content $\rho_{P}$ and growth efficiency $Y_{P}$. In addition, we assume a constant loss rate of $\delta_{P}$. Thus, the equation for the dynamics is given by:

$$
\begin{aligned}
\mathrm{d} P / \mathrm{d} t= & i_{M}+Y_{P} \rho_{P}^{-1} \sum_{j=1}^{j=m}\left[\rho_{B} \alpha_{P U} U_{j}+\left(\rho_{B}+n_{V} \rho_{V}\right) \alpha_{P I} I_{j}\right. \\
& \left.+\rho_{V} \alpha_{P V} V_{j}\right] P-\delta_{P} P-D P
\end{aligned}
$$

where the second term on the right-hand side of Eq. (4) represents the growth process of feeding on all species of bacteria (uninfected and infected cells) and viruses from species 1 to species $m$, and $D P$ is the dilution of protozoa from the system.

Nutrients: We assume that biomass lost from bacteria, viruses, and protozoa, as well as unassimilated nutrients during the growth of bacteria, viruses, and protozoa, return immediately as available nutrients for bacteria. The dynamics of nutrient concentration are given by the following equation:

$$
\begin{aligned}
\mathrm{d} N / \mathrm{d} t & =s_{N}-D N-\sum_{j=1}^{j=m} \alpha_{j} U_{j} N+\sum_{j=1}^{j=m} \rho_{V} \lambda V_{j}+\rho_{P} \delta_{P} P \\
& +\left(1-Y_{B}\right) \sum_{j=1}^{j=m} \alpha_{j} U_{j} N+\left(1-Y_{V}\right) \sum_{j=1}^{j=m}\left(\rho_{B}+n_{V} \rho_{V}\right) L^{-1} I_{j} \\
& +\left(1-Y_{P}\right) \sum_{j=1}^{j=m}\left[\rho_{B} \alpha_{P U} U_{j}+\left(\rho_{B}+n_{V} \rho_{V}\right) \alpha_{P I} I_{j}+\rho_{V} \alpha_{P V} V_{j}\right] P
\end{aligned}
$$

where $s_{N}$ is the continuous supply rate of nutrients, $D N$ is the dilution of nutrients from the system, $\sum_{j=1}^{j=m} \alpha_{j} U_{j} N$ is the total consumption rate by uninfected cells of bacteria from species 1 to species $m$, and $\sum_{j=1}^{j=m} \rho_{V} \lambda V_{j}$ and $\rho_{P} \delta_{P} P$ represent the recycling of lost biomass of all viruses and that of protozoa, respectively. The remaining terms represent the recycling of unassimilated nutrients during the growth of bacteria, viruses, and protozoa, respectively. 

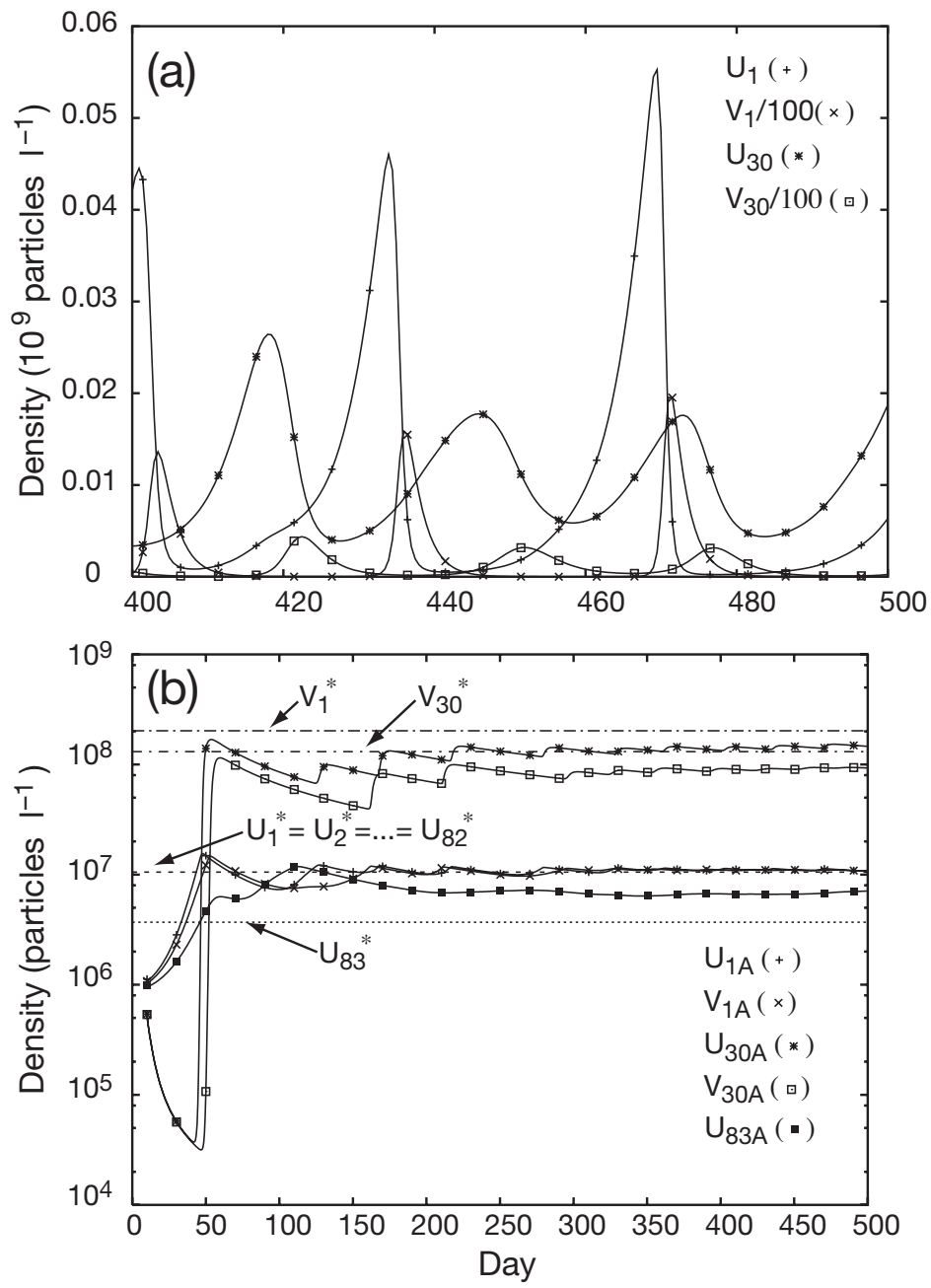

Fig. 2. Model dynamics using the parameters in Table 1. (a) Example of the temporal dynamics of the model food web. This panel represents temporal fluctuations of some variables, showing the dynamics of $U_{1}, U_{30}, V_{1}$ and $V_{30}$. (b) Temporal changes in average values of each variable. Each point at time $t$ represents the average value from time 0 to $t$. Average values tended to approach a stable level after the transient phase, although these values were different from those predicted at equilibrium, which are represented by the 4 dashed lines $\left(V_{1}{ }^{*}, V_{30}{ }^{*}, U_{1}{ }^{*}=U_{2}{ }^{*}=\ldots U_{82}{ }^{*}\right.$, and $\left.U_{83}{ }^{*}\right)$

Model analysis. We assumed a very low rate of immigration $\left(i_{M}=10^{-6} \mathrm{l}^{-1} \mathrm{~d}^{-1}\right)$, so that the abundance of each species is determined almost entirely by interactions within the local system. Generally, local community composition is determined both by immigration from the metacommunity (for a review see Leibold et al. 2004) and by the interactions within the local community. We focused on how the interactions among bacteria, viruses, and protozoa determine bacterial community composition. We first examined the approximate theoretical equilibrium state of the model, assuming there is no immigration. Based on this assumption, we can calculate the density of bacteria, viruses and protozoa, as well as the nutrient concentration (see Appendix 1), and then obtain the BSR at equilibrium, following the calculations by Thingstad (2000). Next, assuming a very low rate of immigration, we examined the temporal dynamics by numerical calculations using the 4th-order Runge-Kutta method, an algorithm for numerically solving differential equations, which achieves high precision at low computational cost (Press et al. 1988). Although the density of each group shows large oscillations (Fig. 2a), the immigration from the metacommunity consisting of $m$ bacteria-virus pairs and protozoa prevents the extinction of any species, and the long-term average density tends to approach some constant value that differs from the equilibrium state (Fig. 2b). The question addressed is how many species are able to dominantly coexist in the community, which is assembled from the very large metacommunity. Here we focused on the number of dominant species whose average density exceeded a certain critical value $\left(S_{D}=10^{6}\right.$ cells l $^{-1}>>$ $i_{M} / D$ ) and which were actually involved in community dynamics. The number of dominant bacterial species with an average density higher than the critical value $S_{D}$ was counted when the average density approached a certain value after a long transient phase, which did not equal the theoretical prediction at equilibrium under the assumption of no immigration. These discrepancies may have been caused by the temporal oscillations. We examined the effects of IGP on BSR and on the food web structure from common trends in theoretical analysis at equilibrium and numerical analysis at non-equilibrium. From the discrepancies between them, we also examined the effects of the temporal oscillations themselves. We chose parameter values that fell within realistic ranges according to the literature and also checked whether the realized densities of bacteria, viruses, and protozoa were reasonable (Table 1).

\section{RESULTS}

\section{Community structure at equilibrium}

At equilibrium, where $\mathrm{d} U_{j} / \mathrm{d} t=\mathrm{d} I_{j} / \mathrm{d} t=\mathrm{d} V_{j} / \mathrm{d} t=$ $\mathrm{d} P / \mathrm{d} t=\mathrm{d} N / \mathrm{d} t=0$, the community composition was determined in the same way as in the KW food web model (see Appendix 1, and Thingstad 2000). The total density of both uninfected and infected bacterial cells at equilibrium, which can be interpreted as the 'carrying capacity', is bounded by the balance between the grazing rate on bacteria and the loss rate of protozoa. However, the density of each bacterial species is deter- 
Table 1. Parameter values used to run the numerical calculations

\begin{tabular}{|c|c|c|c|}
\hline Symbol & Definition & Unit & Default \\
\hline$U_{j}$ & Density of uninfected cells of species $j$ & $10^{9}$ cells $1^{-1}$ & - \\
\hline$I_{j}$ & Density of infected cells of species $j$ & $10^{9}$ cells $1^{-1}$ & - \\
\hline$V_{j}$ & Density of viruses of species $j$ & $10^{9}$ particles $\mathrm{l}^{-1}$ & - \\
\hline$P$ & Density of protozoa & $10^{9}$ cells $\mathrm{l}^{-1}$ & - \\
\hline$N$ & Concentration of nutrient & $\mu g \mathrm{P}^{-1}$ & - \\
\hline$\alpha_{\text {MAX }}$ & Affinity for P of species 1 & $1 \mathrm{~d}^{-1}\left(10^{9} \text { cells }\right)^{-1}$ & $0.1^{\mathrm{a}}$ \\
\hline$\alpha_{M I N}$ & Affinity for $\mathrm{P}$ of species $m$ & $\mathrm{ld} \mathrm{d}^{-1}\left(10^{9} \text { cells }\right)^{-1}$ & $0.01^{\mathrm{b}}$ \\
\hline$\alpha_{j}$ & Affinity for P of species $j$ & $1 \mathrm{~d}^{-1}\left(10^{9} \text { cells }\right)^{-1}$ & $f\left(j, m, \alpha_{M A X} \alpha_{M I N}\right)^{c}$ \\
\hline$m$ & Size of metacommunity & - & $200^{\mathrm{b}}$ \\
\hline$\alpha_{P U}$ & Clearance rate on uninfected cells & $1 \mathrm{~d}^{-1}\left(10^{9} \text { cells }\right)^{-1}$ & $100^{\mathrm{d}}$ \\
\hline$\alpha_{P I}$ & Clearance rate on infected cells & $1 \mathrm{~d}^{-1}\left(10^{9} \text { cells }\right)^{-1}$ & $1.0 \alpha_{P U}^{\mathrm{b}}$ \\
\hline$\alpha_{P V}$ & Clearance rate on free-living viruses & $1 \mathrm{~d}^{-1}\left(10^{9} \text { cells }\right)^{-1}$ & $0.01 \alpha_{P U}^{\mathrm{b}}$ \\
\hline$\delta_{P}$ & Loss rate of protozoa & $d^{-1}$ & $0.25^{\mathrm{b}}$ \\
\hline$\beta$ & Infection rate & $1 \mathrm{~d}^{-1}\left(10^{9} \text { cells }\right)^{-1}$ & $1.0^{\mathrm{e}}$ \\
\hline$\lambda$ & Loss rate of viruses & $\mathrm{d}^{-1}$ & $0.5^{\mathrm{f}}$ \\
\hline$L$ & Latent period & Day & $1.0 / 24.0^{\mathrm{g}}$ \\
\hline$Y_{P}$ & Growth efficiency of protozoa & - & $0.3^{\mathrm{h}}$ \\
\hline$Y_{B}$ & Growth efficiency of bacteria & - & $0.3^{\mathrm{h}}$ \\
\hline$Y_{V}$ & Growth efficiency of viruses & - & $0.5^{\mathrm{i}}$ \\
\hline$\rho_{B}$ & Nutrient content of bacteria & $\mu g \mathrm{P}\left(10^{9} \text { cells }\right)^{-1}$ & $1.0^{\mathrm{j}}$ \\
\hline$\rho_{V}$ & Nutrient content of viruses & $\mu \mathrm{g} P\left(10^{9} \text { particles }\right)^{-1}$ & $0.01^{\mathrm{k}}$ \\
\hline$\rho_{P}$ & Nutrient content of protozoa & $\mu \mathrm{g} P\left(10^{9} \text { cells }\right)^{-1}$ & $100^{1}$ \\
\hline$n_{V}$ & Number of virus per cell & Particles cell ${ }^{-1}$ & $1^{\mathrm{b}}$ \\
\hline$s_{N}$ & Supply rate of nutrient & $\mu g \mathrm{P}^{-1} \mathrm{~d}^{-1}$ & $0.2^{\mathrm{b}}$ \\
\hline$D$ & Dilution rate & $\mathrm{d}^{-1}$ & $0.01^{b}$ \\
\hline$i_{M}$ & Immigration rate of microorganisms & $10^{9}$ particles $\mathrm{l}^{-1}$ & $10^{-15 b}$ \\
\hline$S_{D}$ & Threshold for counting BSR & $10^{9}$ cells $\mathrm{l}^{-1}$ & $10^{-3 \mathrm{~b}}$ \\
\hline Total $B^{*}$ & Calculated default values & $10^{9}$ cells $1^{-1}$ & 0.870262 \\
\hline Total $V^{*}$ & Calculated default values & $10^{9}$ particles $\mathrm{l}^{-1}$ & 8.400775 \\
\hline$P^{*}$ & Calculated default values & $10^{9}{\text { cells } 1^{-1}}$ & 0.003362 \\
\hline$T_{N}^{*}$ & Total nutrient in the system $\left(=D^{-1} s_{N}\right)$ & $\mu g \mathrm{Pl}^{-1}$ & 20 \\
\hline \multicolumn{4}{|c|}{${ }^{a}$ Maximum affinity for $\mathrm{P}$ was assumed for the growth rate $Y_{B} \alpha_{\mathrm{MAX}} N$ on the order of $\sim 0.1$ to $1.0 \mathrm{~d}^{-1}$} \\
\hline \multicolumn{4}{|c|}{${ }^{\mathrm{c}}$ The affinity for P of species $j$ was determined by $f\left(j, m_{1} \alpha_{M A X}, \alpha_{M I N}\right)=\alpha_{\text {MAX }}-\left(\alpha_{\mathrm{MAX}}-\alpha_{M I N}\right) m^{-1}(j-1)$} \\
\hline \multicolumn{4}{|c|}{$\begin{array}{l}\text { d Assuming the protozoa density to be on the order of } 10^{-3} \times 10^{9} \mathrm{l}^{-1} \text {, values were assumed for bacterial mortality from proto- } \\
\text { zoan grazing }\left(\alpha_{P U} P\right) \text { to be on the order of } 0.1 \mathrm{~d}^{-1}\end{array}$} \\
\hline \multicolumn{4}{|c|}{$\begin{array}{l}\text { e The value for bacterial morality from viral lysis was assumed to be on the same order as mortality from protozoan grazing, } \\
\text { assuming each viral density to be on the order of } 10^{-1} \times 10^{9} \mathrm{l}^{-1}\end{array}$} \\
\hline \multicolumn{4}{|c|}{${ }^{\mathrm{f}}$ The value was determined by the lower value in Suttle \& Chen (1992) } \\
\hline \multicolumn{4}{|c|}{${ }^{9}$ Taken from Middelboe (2000) } \\
\hline \multirow{2}{*}{\multicolumn{4}{|c|}{$\begin{array}{l}{ }^{\mathrm{h}} \text { Values for protozoa and bacteria were determined from Sterner \& Elser }(2002) \text { and del } \\
{ }^{\mathrm{i}} \text { The value was assumed for the burst size } Y_{V}\left(\rho_{B} / \rho_{V}+n_{V}\right) \text { to be on the order of } 5.0 \times 10^{1}\end{array}$}} \\
\hline & & & \\
\hline \multicolumn{4}{|c|}{ 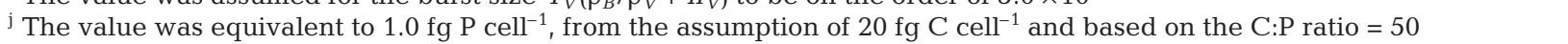 } \\
\hline \multicolumn{4}{|c|}{$\begin{array}{l}{ }^{\mathrm{k}} \text { The value was on the order of } 0.01 \mathrm{fg} \mathrm{P} \text { particle }{ }^{-1} \text {, from the data that } 0.087 \mathrm{fg} \text { DNA particle }{ }^{-1} \text { (Borsheim et al. 1990) and } 8.7 \% \\
\text { P in DNA (Sterner \& Elser 2002) }\end{array}$} \\
\hline $\begin{array}{l}\mathrm{P} \text { in } \mathrm{DN} \\
{ }^{1} \text { The valu }\end{array}$ & $\begin{array}{l}\text { er \& Elser 2002) } \\
n \text { the order of } 100 \text { times that of bacteria }\end{array}$ & & \\
\hline
\end{tabular}

mined by the balance between the infection and loss rates of specific viruses. Therefore, only a finite number of bacterial species can be supported by this carrying capacity. Let this finite number be $n(<m)$, then species $j(j>n)$ are competitively excluded, as they are less competitive than species $k(k \leq n)$ because of their lower nutrient affinity. Among the bacterial species $k$ $(k=1,2, \ldots, n)$, which are members of the realized community, the first to $(n-1)$ th species are infected by their specific viruses. The $n$th bacterial host is able to estab- lish a population, but its density is not sufficient for its virus to establish a population. It follows that $(n-1)$ host-virus pairs, $n$th virus-free host, and protozoa will coexist in the whole microbial food web at equilibrium (see Fig. 1). Note that the density of the virus decreases with decreasing nutrient affinity of its host $\left(V_{1}{ }^{*}>V_{2}{ }^{*}>\right.$ $\ldots>V_{n-1}{ }^{*}$; see Eq. A5 in Appendix $1 ;{ }^{*}$ value at theoretical equilibrium with no immigration). This results in decreasing the attack rate on hosts $\left(\beta V_{1}{ }^{*}>\beta V_{2}{ }^{*}>\ldots>\right.$ $\left.\beta V_{n-1}{ }^{*}\right)$, which is the same prediction as made by 


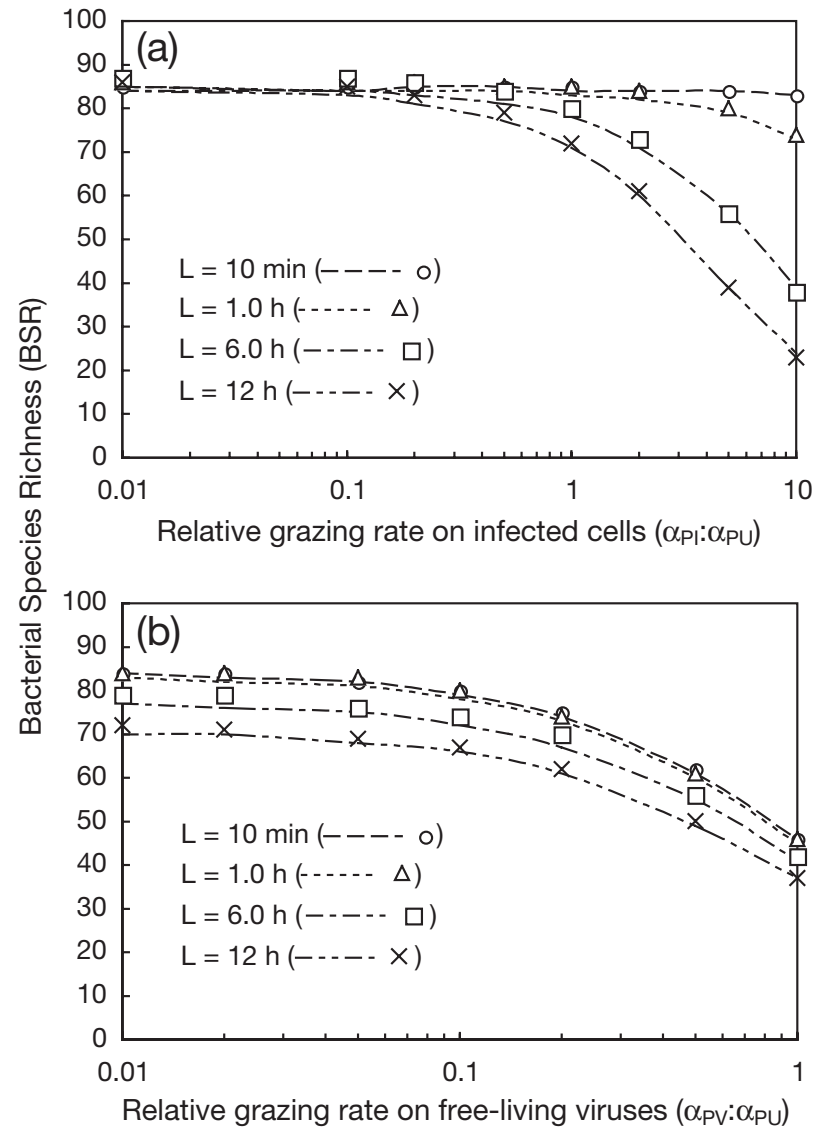

Fig. 3. Effects of coincidental and omnivorous IGP on bacterial species richness (BSR). Each point represents the results from numerical calculations $\left(\mathrm{BSR}_{A}\right)$, and dashed lines are based on the theoretical prediction at equilibrium $\left(\mathrm{BSR}^{*}\right)$. Different symbols and lines correspond to the results from different periods of latency ( $L=10 \mathrm{~min}, 1 \mathrm{~h}, 6 \mathrm{~h}$, and $12 \mathrm{~h}$ ). (a) Response to relative grazing rate on infected cells compared to uninfected cells $\left(\alpha_{P I}: \alpha_{P U}\right)$. (b) Response to relative grazing rate on free-living viruses compared to uninfected cells $\left(\alpha_{P V}: \alpha_{P U}\right)$. Parameters used were: (a) $\alpha_{P V}=0.01$, (b) $\alpha_{P I}=$ $\alpha_{P U}$. Other parameters as in Table 1

Thingstad (2000). It follows that the density of uninfected cells from the first to $(n-1)$ th bacterial species is maintained equally despite decreasing nutrient affinity, and that the density of the $n$th species is lowered $\left(U_{1}{ }^{*}=U_{2}{ }^{*}=\ldots=U_{n-1}{ }^{*}>U_{n}{ }^{*}\right.$; see Eq. A3 in Appendix 1). However, the density of infected cells of each bacterial species decreases with decreasing affinity $\left(I_{1}{ }^{*}>I_{2}{ }^{*}>\ldots>I_{n-1}{ }^{*}\right.$; see Eq. A2 in Appendix 1), as does the total density of each bacterial species $\left(U_{j}+I_{j}\right)$. Using default values in Table 1, we confirmed that total bacterial density, total virus density, and the density of protozoa fell into reasonable ranges, approximately on the order of $10^{9}, 10^{10}$ and $10^{6} \mathrm{l}^{-1}$, respectively. In addition, for nutrient dynamics we introduced the total nutrients $\left(T_{N}\right)$ into the system as follows:

$$
\begin{aligned}
T_{N}= & N+\sum_{j=1}^{j=m} \rho_{B} U_{j}+\sum_{j=1}^{j=m}\left(\rho_{B}+n_{V} \rho_{V}\right) I_{j}+ \\
& \sum_{j=1}^{j=m} \rho_{V} V_{j}+\rho_{P} P
\end{aligned}
$$

which represents the sum of nutrients available for bacteria and nutrient biomass in uninfected and infected bacterial cells (from species 1 to species $m$ ), in viruses (from species 1 to species $m$ ), and in protozoa.

Using Eqs. (1) to (5), we can then determine that the dynamics $T_{N}$ are given by the following simple equation (Appendix 1):

$$
\mathrm{d} T_{N} / \mathrm{d} t=s_{N}-D T_{N}
$$

where $D T_{N}$ represents dilution of total nutrients

Therefore, from $\mathrm{d} T_{N} / \mathrm{d} t=0$, the following equation should be satisfied at equilibrium with no immigration:

$$
T_{N}^{*}=D^{-1} S_{N}
$$

where $T_{N}{ }^{*}$ represents the trophic status of the system.

\section{Numerical investigation of the effect of IGP}

Here, we must note again that the temporal dynamics did not reach equilibrium (Fig. 2a); this is in contrast to the stable behavior observed in the KW food web model, which does not assume a latent period of viruses (Thingstad 2000). The long-term averages of each component approached certain values, but these differed from the equilibrium (Fig. 2b). Fig. 2b shows that multiple bacterial species were able to coexist, suggesting that the KW processes, which prevent competitive exclusion by the winner of the nutrient competition, are able to work effectively even with the existence of IGP. Numerical calculations showed that realized BSR $\left(n_{A}\right.$, where $A$ represents long-term average values) does not depend on the size of the metacommunity $(m)$ if $m$ is chosen as a number sufficiently larger than the predicted species richness $n^{*}\left(\mathrm{BSR}^{*}\right)$ at equilibrium.

Next, we examined how IGP processes influence BSR. Fig. 3a shows how BSR is determined by the grazing rate on infected cells $\left(\alpha_{P I}\right)$ compared to the rate on uninfected cells $\left(\alpha_{P U}\right)$, i.e. the effect of coincidental IGP on BSR. We can explain the common patterns in both $\mathrm{BSR}^{*}$ and $\mathrm{BSR}_{A}$ because the difference between them is very small. When the latent period is short $(L=$ $10 \mathrm{~min}$ and $1.0 \mathrm{~h}$ ), BSR is not influenced by the relative grazing rate on infected cells $\left(\alpha_{P I} / \alpha_{P U}\right)$. However, when the latent period is long ( $L=6.0$ and $12 \mathrm{~h}$ ), BSR decreases with increasing rate of IGP. Here, $\alpha_{P I} / \alpha_{P U}=$ 1.0 indicates completely non-selective grazing where the grazing rate on both uninfected and infected cells of every bacterial species is equal. When $\alpha_{P I} / \alpha_{P U}<1.0$, grazing is selective for uninfected cells, and when 
$\alpha_{P I} / \alpha_{P U}>1.0$, grazing is selective for infected cells. Although Fig. 3a shows the potential responses of BSR to an increase in the relative grazing rate on infected bacterial cells $\left(\alpha_{P I} / \alpha_{P U}\right)$, it is likely that protozoa cannot distinguish infected from uninfected bacterial cells. Therefore, we set $\alpha_{P I} / \alpha_{P U}=1.0$ in the analyses when investigating the effects of IGP. Fig. 3b shows how BSR is affected by the grazing on free-living viruses (the effect of omnivorous IGP). This suggests that BSR theoretically can decrease with an increasing relative grazing rate on free-living viruses $\left(\alpha_{P V} / \alpha_{P U}\right)$.

We also examined how the latent period affects BSR through changes in the intensity of coincidental IGP and the food web structures. Although the analysis at equilibrium (BSR*; Fig. 4a) predicts that BSR is relatively constant, independent of the latent period when infected cells are not grazed $\left(\alpha_{P I} / \alpha_{P U}=0.0\right)$, the analysis at nonequilibrium $\left(\mathrm{BSR}_{A} ;\right.$ Fig. $\left.4 \mathrm{a}\right)$ shows that $\mathrm{BSR}_{A}$ is lower than BSR* when the latent period is long ( $L \geq 2.0 \mathrm{~d}$ ) and that it decreases with increasing latent period. This implies that this reduction is caused by temporal oscillations in the system, not by IGP. However, when infected cells are equally grazed $\left(\alpha_{P I} / \alpha_{P U}=1.0\right)$, the degree of reduction of $\mathrm{BSR}_{A}$ is larger than for those without IGP $\left(\alpha_{P I} / \alpha_{P U}=0.0\right)$. Thus, the difference between the 2 values actually corresponds to the effects of IGP on $\mathrm{BSR}_{A}$. This difference can be explained by the different patterns of change in the abundance of bacteria, viruses, and protozoa. Fig. $4 \mathrm{~b}$ shows that the changes in the total abundance of bacteria (B), which is the sum of uninfected and infected cells of all species, the frequency of infected cells $(\mathrm{I}: \mathrm{B})$, and the relative abundance of protozoa $(\mathrm{P}: \mathrm{B})$ have the same patterns in food webs without IGP $\left(\alpha_{P I} / \alpha_{P U}=0.0\right)$ and with IGP $\left(\alpha_{P I} / \alpha_{P U}=1.0\right)$. The total density of bacteria and the relative density of protozoa are constant, but the frequency of infected bacteria increases with an increasing latent period. However, compared to food webs with IGP, viral abundance in food webs without IGP is less influenced by the latent period, leading to a decreased reduction in BSR. This is because infected cells are not vulnerable to grazing by protozoa. However, with non-selective grazing $\left(\alpha_{P I} / \alpha_{P U}=1.0\right)$, an increasing frequency of infected cells (I:B) makes viruses in infected hosts more vulner-
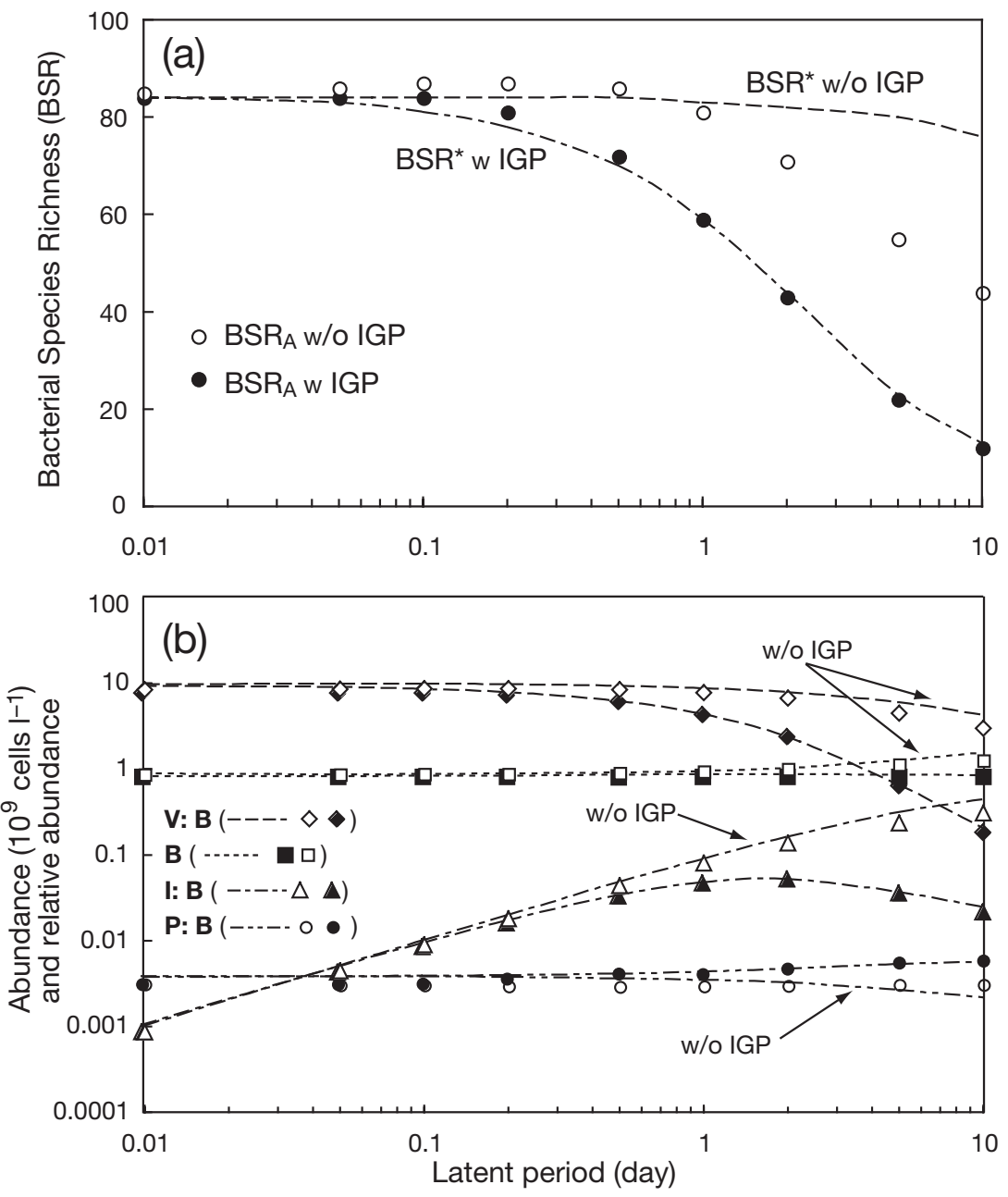

Fig. 4. Effects of the latent period on (a) BSR and (b) abundance of bacteria, viruses, and protozoa. Each dashed line represents the theoretical prediction at equilibrium, and each symbol represents the results from numerical calculations. Open and closed symbols represent the results from cases without (w/o) $\left(\alpha_{P I}=0.0\right)$ and with $(\mathrm{w})\left(\alpha_{P I}: \alpha_{P U}=1.0\right)$ coincidental IGP, respectively. Parameter used was: $\alpha_{P V}=0.01 \alpha_{P U}$. Other parameters as in Table 1. B: total abundance of bacteria $\left(10^{9}\right.$ cells $\left.\mathrm{l}^{-1}\right)$; V:B: relative abundance of viruses; P:B: relative abundance of protozoa; I:B: frequency of infected cells

able to being killed by protozoa, leading to a lower abundance of viruses (lower $\mathrm{V}$ :B ratio). It follows that the KW process is highly reduced. In addition, the predicted values at equilibrium when $L=0 \mathrm{~d}$, which are not shown in Fig. 4, are almost the same as when $L=$ $0.01 \mathrm{~d}$. In fact, $L=0$ corresponds to the pure KW process, because $L=0$ represents immediate bacterial lysis after viral infection (which is mathematically justified; see Appendix 2).

Finally, we examined how environmental changes cause changes in food web structure and thus changes in BSR. We focused on the changes in the loss rate of protozoa $\left(\delta_{P}\right)$, representing top-down regulation on 


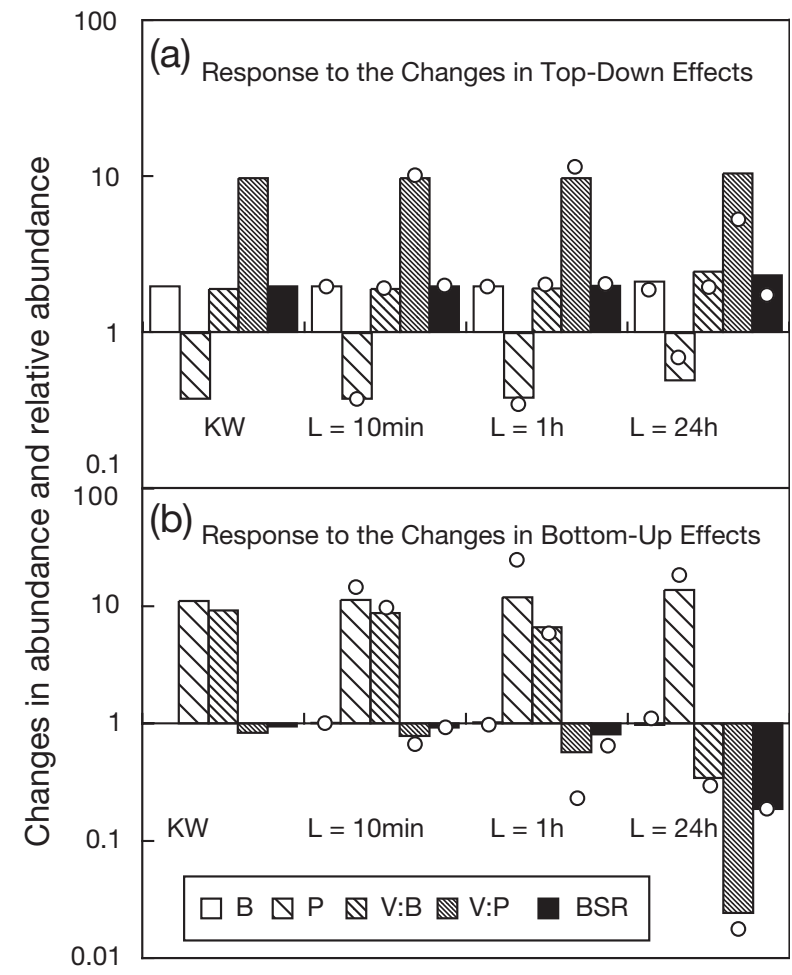

Fig. 5. Responses of abundance of bacteria, viruses, and protozoa, and BSR to the changes in top-down and bottom-up effects. Each bar (prediction at equilibrium) and point (prediction at non-equilibrium state) represents the relative change in total abundance of bacteria (B), abundance of protozoa $(\mathrm{P})$, virus to bacteria ratio $(\mathrm{V}: \mathrm{B})$, virus to protozoa ratio (V:P), and bacterial species richness (BSR). (a) Response to a 2 -fold increase in the loss rate of protozoa $\left(\delta_{P}\right)$. (b) Response to a 10 -fold increase in the nutrient supply rate $\left(s_{N}\right)$. Parameters used as in Table 1

protozoa (Fig. 5a), and in the supply rate of nutrients $\left(s_{N}\right)$, which determines the trophic status $\left(T_{N}=D^{-1} S_{N}\right)$, representing bottom-up regulation (Fig. 5b). In Fig. 5, each bar (prediction at equilibrium) and point (prediction at non-equilibrium state) represents the relative change in each variable when $\delta_{P}$ or $s_{N}$ become 2 or 10 times higher, respectively, and where a value greater (or less) than 1.0 indicates increases (or decreases) in each variable with increased $\delta_{P}$ or $s_{N}$. Fig. 5a represents changes in the abundance of bacteria (B), abundance of protozoa $(\mathrm{P})$, virus to bacteria ratio $(\mathrm{V}: \mathrm{B})$, virus to protozoa ratio $(\mathrm{V}: \mathrm{P})$, and $\mathrm{BSR}$ when $\delta_{P}$ is doubled from 0.25 to 0.5 . This figure shows that increasing topdown regulation on protozoa (heterotrophic flagellates) by larger predators (e.g. 'ciliates') leads to a decrease in the density of protozoa, resulting in an increase in the total density of bacteria. At the same time, the structure of the food web is changed; the V:B and the V:P abundance ratios increase, resulting in an increased BSR (e.g. from 84 to 166 when $L=10 \mathrm{~min}$ ).
Note that the pattern of changes does not depend on the latent period, i.e. it does not matter whether the intensity of IGP is high $(L=24 \mathrm{~h}$ ) or low (pure KW process $[L=0]$ and $L=10 \mathrm{~min}, 1.0 \mathrm{~h}$ ). However, the response to eutrophication (total nutrient concentration increases 10 times, from $20 \mu \mathrm{g} \mathrm{P} \mathrm{l}^{-1}$ to $200 \mu \mathrm{g} \mathrm{P} \mathrm{l}^{-1}$, by increasing the supply rate of nutrients from 0.2 to $2.0 \mu \mathrm{g} \mathrm{P}^{-1} \mathrm{~d}^{-1}$ ) largely depends on whether the intensity of IGP is high or low (Fig. 5b). When the latent period is short $(L=10 \mathrm{~min}, 1.0 \mathrm{~h})$, both protozoa and viruses increase with increasing total nutrients in the system, and then the V:P abundance ratio is relatively constant, resulting in a constant BSR, as is the case with the pure KW process $(L=0)$. However, when the latent period is long $(L=24 \mathrm{~h})$, increasing total nutrients leads to a decrease in the $\mathrm{V}: \mathrm{P}$ and $\mathrm{V}: \mathrm{B}$ ratios, resulting in a substantial decrease in the BSR (from 59 to 11). Increasing total nutrients leads to a higher production of bacteria, which results in positive effects on both protozoa and viruses. However, the increase in protozoa abundance negatively affects viruses through IGP. Fig. 5b shows that the net effect of eutrophication on viruses is negative when IGP is strong with a long latent period.

\section{DISCUSSION}

In pelagic environments, relative body size is one of the key factors influencing the direction and frequency of trophic links ('size-structured food webs'; Sheldon et al. 1972, Azam et al. 1983). Therefore, protozoan predators inevitably eat viruses when they eat the bacterial host. This coincidental IGP occurs frequently between protozoa and viruses. However, omnivorous direct IGP on free-living viruses is not as frequent (González \& Suttle 1993), probably because the difference in body size between protozoa and viral particles is too large (Sherr \& Sherr 2000). Using a simple extension of the KW food web model, we demonstrated that coincidental IGP, with the same attack rate on uninfected and infected cells $\left(\alpha_{P I}=\alpha_{P U}\right)$, causes a reduction in BSR. We also predicted that preferential grazing on infected cells $\left(\alpha_{P I}>\alpha_{P U}\right)$ has a larger potential impact on BSR than non-selective grazing $\left(\alpha_{P I}=\alpha_{P U}\right)$. This could occur if bacterial physiology or behavior changed drastically after viral infection, and if this led to increased vulnerability to protozoa, although no evidence for this is available. In contrast omnivorous IGP within the realistic range $\left(\alpha_{P V} / \alpha_{P U}<0.1\right.$, e.g. 2.6 to $4.8 \%$ of grazing rate on bacterial cells; González \& Suttle 1993) had little effect on BSR, although it had a potentially negative effect on BSR (Fig. 3b). These IGP processes can also be interpreted as an 'eating your competitor' strategy of protozoa, which was previously 
proposed for mixotrophic protists (Thingstad et al. 1996). From this point of view, protozoa benefit from grazing on viruses by (1) removing viruses as competitors for bacteria, and (2) obtaining additional nutrients from viruses, although the nutrient content of viruses alone would be insufficient for protozoa. With these 2 mechanisms, increased IGP leads to decreases in the abundance of the competitor (viruses) and indirectly causes a reduction in BSR.

The latent period of viruses $(L)$ is also a key parameter determining the intensity of coincidental IGP. The difference in predicted BSR between a pure KW process with no latent period $(L=0)$ and the KKW process with a latent period $(L>0)$ is negligible when the latent period is short (Fig. 4). However, the difference increases with increasing latent period. Increasing the latent period indirectly leads to a reduction in the abundance of viruses by making viruses in host cells more vulnerable to being killed by protozoa. In particular, Fig. 4b suggests that viral abundance decreases with an increasing latent period, whereas protozoan abundance remains relatively constant. It follows that a decreased infection rate of viruses leads to looser packing of each species of bacteria into the constant carrying capacity that is maintained by the less variable protozoan grazing rate, which results in a reduction of BSR. Furthermore, the changes in food web structure and BSR along a trophic gradient can be very different between a case with a long latent period, i.e. in KKW processes with high IGP ( $L=24 \mathrm{~h})$, and a case with a short or no latent period, i.e. in KKW processes with low IGP ( $L=10 \mathrm{~min}, 1.0 \mathrm{~h}$ ) or in pure KW processes with no IGP $(L=0)$. Changes in food web structure (e.g. $\mathrm{V}: \mathrm{B}$ and $\mathrm{V}: \mathrm{P}$ ratios) are also related to changes in material flow within the microbial loop. A high V:P ratio leads to higher BSR but also results in greatly increased nutrient flow from bacteria to viruses (viral loop; Fuhrman 1999) rather than from bacteria to protozoa (microbial loop; Azam et al. 1983). When the latent period is very short $(L=10 \mathrm{~min})$, the model analysis predicts that eutrophication (increasing total nutrient concentrations) does not change the relative flow from bacteria to viruses compared to the flow from bacteria to protozoa, which is the same as the prediction for the pure KW process $(L=0)$. However, when the latent period is substantially longer, which is the case in the KKW situation with high IGP, eutrophication will change the food web structure, leading to a low V:P ratio. This also means that the nutrient pathway from bacteria to protozoa and from viruses to protozoa will be strengthened, whereas the pathway from bacteria to viruses will be diminished. This suggests that viruses have much more impact on nutrient cycling in relatively oligotrophic environments if the latent period of viruses is not negligible, i.e. in a KKW situation with high IGP. In addition to the impacts on nutrient cycling, another important prediction is that eutrophication leads to a reduction of BSR if the latent period of the viruses is long.

It is generally suggested that the viral loop enhances the recycling of nutrients to bacteria, leading to higher bacterial production compared to situations without viruses (Fuhrman 1999). However, because host-specific viral infection suppresses the growth of bacterial species with a higher affinity for nutrients, the existence of viruses leads to less effective use of nutrients for production throughout the bacterial community, instead of higher species richness. In this model, for example, in the case of Fig. 3a, total bacterial production with $\alpha_{P I} / \alpha_{P U}=0.01$ and $L=12 \mathrm{~h}$ (with low IGP), and $\alpha_{P I} / \alpha_{P U}=10.0$ and $L=12 \mathrm{~h}$ (with high IGP) is 1.06 and $1.45 \mu \mathrm{g} \mathrm{P} \mathrm{l}^{-1} \mathrm{~d}^{-1}$, respectively, and in the case of Fig. $4 \mathrm{a}$, production with $\alpha_{P I} / \alpha_{P U}=1.0$ and $L=0.01 \mathrm{~d}$ (with low IGP) and $\alpha_{P I} / \alpha_{P U}=1.0$ and $L=$

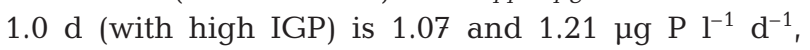
respectively. This means that increasing IGP leads to higher bacterial production. These opposing effects of viruses on BSR and bacterial community production are suggested only by this idealized food web model in which every bacterial species competes for unique nutrients. Therefore, for a generalization of the functions of viruses, more realistic situations should be considered, in which bacteria use many types of resources.

The BSR predicted by our KKW model ranges from 10 to about 160, which falls into approximately the same order as previous predictions - 100 in the model based on the KW hypothesis (Thingstad et al. 1997) and 160 based on the species rank-abundance curve model (Curtis et al. 2002). We can compare these values to 2 observed extreme estimates of bacterial diversity. From a PCR-based analysis of a small subunit of rRNA, an estimate of 10 to 30 (e.g. Murray et al. 1996) was obtained. However, from an analysis of the whole genome shotgun sequence, the estimate was at least 1800 (Venter et al. 2004). Thus, our prediction is closer to the PCR-based method than to the shotgun sequence. Although this large discrepancy must be carefully considered and solved empirically (for a review see Curtis \& Sloan 2004, Weinbauer \& Rassoulzadegan 2004), here we will discuss one of the possibilities from a theoretical viewpoint. It is possible that the estimate from the whole genome shotgun sequence represents the size of the metacommunity, because even very rare bacterial genomes in the environment will be included in this estimate. In contrast, PCR-based methods are able to detect only abundant phylogenetic groups in the environment. The problem that 'universal' primers are not universal is also responsible for the underestimation of species richness in PCR-based analyses (e.g. Hongoh et al. 2003). It is 
natural to assume that these methods can roughly estimate the number of dominant bacterial species. The estimated of $\sim 10$ to 30 species is in agreement with that of our KKW model, which can be lower than the estimate from the model based on the pure KW process, depending on the relative grazing rate on infected cells and the latent period.

The equilibrium of this model is not locally stable within the realistic region of parameter values, which is quite different from the original KW food web model (Thingstad 2000). This may be caused by the introduction of the infected population reflecting the latency of viruses, which generates a time delay between viral infection and bacterial lysis and results in the destabilization of the system (Levin et al. 1977, Thingstad 2000). Because of large fluctuations, the densities of bacteria and viruses sometimes become very low, although they never reach zero even without immigration if the equilibrium value with no immigration is positive (e.g. $U_{j}$ never reaches zero if $U_{j}^{*}$ is positive). However, this coexistence is not ecologically reasonable, because stochastic environmental fluctuations in natural ecosystems easily cause the extinction of species whose density becomes very low. Thus, immigration is a crucial assumption for the maintenance of bacterial coexistence. Note that this type of dynamic behavior is not usually observed in large natural systems, although some theoretical models of competitive interactions and small biological treatment systems often show unstable dynamics (for review see Curtis \& Sloan 2004). Therefore, some stabilizing factors should be incorporated to better understand the community dynamics in natural systems. We found that the analysis at equilibrium with no immigration was a good approximation for describing community composition at non-equilibrium with a very small immigration rate. Temporal oscillations did not affect most aspects of our predictions of how IGP influences BSR through changes in food web structures. Generally, because temporal oscillations have both positive effects (by relaxing interspecific competition; Huston 1979) and negative effects (by posing stress on species with low growth rates; Huston 1979), the net effect on the number of coexisting species can be either positive or negative (Huston 1979, Armstrong \& McGehee 1989, Huisman \& Weissing 1999). In this model, the temporal oscillations caused by latency have little effect on BSR when the latent period is short ( $L \leq 1 \mathrm{~d}$ ), noting that $\mathrm{BSR}^{*}$ at equilibrium is almost the same as $\mathrm{BSR}_{A}$ at nonequilibrium. It is only when the latent period is long ( $L \geq 2$ d) that temporal oscillations have negative effects on BSR even without the influences of IGP (Fig. 4a).

Other recent studies have also begun to counterbalance the notion of KW processes. Some studies have suggested that the impact of viruses on bacterial community composition is lower than expected because of the existence of resistant strains of bacteria (Middelboe et al. 2001, Schwalbach et al. 2004). This bacterial resistance may also be another type of KKW process in which bacterial cells themselves 'kill' viruses ('killer of the winner'), thereby reducing viral infection rate and leading to lower BSR. Wichels et al. (1998) suggested that interactions between hosts and viruses are not as specific as in the KW hypothesis; these authors showed that 1 bacterial species (or strain) can be infected by multiple viral species and also that 1 viral species can infect multiple types of host. The inter-specific competition among viruses for hosts caused by low host specificity may lead to lower species richness of viruses. This will also result in lower BSR. Overly complicated modifications of the simple KW model and new theories for the sake of presenting theories should not be explored. However, our study is one of the necessary steps in a natural expansion of the KW model to further our understanding of bacteria-virus-protozoa interactions and their effects on biodiversity, community structure, and biogeochemical cycling in microbial ecosystems.

Acknowledgements. We thank the members of our microbial ecology seminar, especially Dr. T. Yokokawa and Dr. T. Nagata, for their valuable suggestions, and 3 anonymous reviewers for their helpful comments on the manuscript. This study was partly supported by a Grant for Biodiversity Research of the 21st Century COE (A14). T.M. was also partly supported by the Japan Society for the Promotion of Science Research Fellowships for Young Scientists.

\section{LITERATURE CITED}

Anderson RM, May RM (1992) Infectious diseases of humans: dynamics and control. Oxford University Press, Oxford

Armstrong RA, McGehee R (1980) Competitive exclusion. Am Nat 115:151-170

Azam F, Fenchel T, Field JG, Gray JS, Meyer-Reil LA, Thingstad F (1983) The ecological role of water-column microbes in the sea. Mar Ecol Prog Ser 10:257-263

Bianchi A, Bianchi M (1995) Bacterial diversity and ecosystem maintenance: an orverview. In: Allsopp D, Colwell RR, Hawksworth DL (eds) Microbial diversity and ecosystem function. CAB International, Wallingford, p 185-198

Binder B (1999) Reconsidering the relationship between virally induced bacterial mortality and frequency of infected cells. Aquat Microb Ecol 18:207-215

Borsheim KY, Bratbak G, Heldal M (1990) Enumeration and biomass estimation of planktonic bacteria and viruses by transmission electron-microscopy. Appl Environ Microbiol 56:352-356

Bratbak G, Heldal M, Thingstad TF, Riemann B, Haslund OH (1992) Incorporation of viruses into the budget of microbial C-tranfer. A first approach. Aquat Microb Ecol 83:273-280

Curtis TP, Sloan WT (2004) Prokaryotic diversity and its limits: microbial community structure in nature and implications for microbial ecology. Curr Opinion Microbiol 7:221-226 
Curtis TP, Sloan WT, Scannell JW (2002) Estimating prokaryotic diversity and its limits. Proc Natl Acad Sci USA 99:10494-10499

del Giorgio PA, Cole JJ (1998) Bacterial growth efficiency in natural aquatic systems. Annu Rev Ecol Syst 29:503-541

Fenchel T, Esteban GF, Finlay BJ (1997) Local versus global diversity of microorganisms: cryptic diversity of ciliated protozoa. Oikos 80:220-225

Fuhrman JA (1999) Marine viruses and their biogeochemical and ecological effects. Nature 399:541-548

Fuhrman JA, Schwalbach M (2003) Viral influence on aquatic bacterial communities. Biol Bull (Woods Hole) 204: 192-195

González JM, Suttle CA (1993) Grazing by marine nanoflagellates on viruses and virus-sized particles - ingestion and digestion. Mar Ecol Prog Ser 94:1-10

Hewson I, Vargo GA, Fuhrman JA (2003) Bacterial diversity in shallow oligotrophic marine benthos and overlying waters: effects of virus infection, containment, and nutrient enrichment. Microb Ecol 46:322-336

Hillebrand H, Watermann F, Karez R, Berninger UG (2001) Differences in species richness patterns between unicellular and multicellular organisms. Oecologia 126:114-124

Holt RD, Polis GA (1997) A theoretical framework for intraguild predation. Am Nat 149:745-764

Hongoh Y, Yuzawa H, Ohkuma M, Kubo T (2003) Evaluation of primers and PCR conditions for the analysis of $16 \mathrm{~S}$ rRNA genes from a natural environment. FEMS Microbiol Lett 221:299-304

Huisman J, Weissing FJ (1999) Biodiversity of plankton by species oscillations and chaos. Nature 402:407-410

Huston M (1979) A general hypothesis of species diversity. Am Nat 113:81-101

Lee SH, Satoh H, Katayama H, Mino T (2004) Isolation, physiological characterization of bacteriophages from enhanced biological phosphorus removal activated sludge and their putative role. J Microbiol Biotechnol 14:730-736

Leibold MA, Holyoak M, Mouquet N, Amarasekare P and 8 others (2004) The metacommunity concept: a framework for multi-scale community ecology. Ecol Lett 7:601-613

Levin BR, Stewart FM, Chao L (1977) Resource-limited growth, competition, and predation: a model and experimental studies with bacteria and bacteriophage. Am Nat 111:3-24

Malchow H, Hilker FM, Petrovskii SV, Brauer K (2004) Oscillations and waves in a virally infected plankton system. Part I: The lysogenic stage. Ecol Complex 1:211-223

Manage PM, Kawabata Z, Nakano S, Nishibe Y (2002) Effect of heterotrophic nanoflagellates on the loss of virus-like particles in pond water. Ecol Res 17:473-479

Middelboe M (2000) Bacterial growth rate and marine virushost dynamics. Microb Ecol 40:114-124

Middelboe M, Hagström Å, Blackburn N, Sinn B and 5 others (2001) Effects of bacteriophages on the population dynamics of four strains of pelagic marine bacteria. Microb Ecol 42:395-406

Murray AE, Hollibaugh JT, Orrego C (1996) Phylogenetic compositions of bacterioplankon from two California estuaries compared by denaturing gradient gel electrophoresis of $16 \mathrm{~S}$ rDNA Fragments. Appl Environ Microbiol 62:2676-2680

Noble RT, Fuhrman JA (1998) Use of SYBR Green I for rapid epifluorescence counts of marine viruses and bacteria. Aquat Microb Ecol 14:113-118
Polis GA, Myers CA, Holt RD (1989) The ecology and evolution of intraguild predation - potential competitors that eat each other. Annu Rev Ecol Syst 20:297-330

Press WH, Teukolsky SA, Vetterling WT, Flannery BP (1988) Numerical recipes in $C$ : the art of scientific computing. Cambridge University Press, Cambridge, p 707-752

Schlegel HG, Jannasch HW (1981) Prokaryotes and their habitats. In: Starr, MP, Stolp H, Trüper HG, Balows A, Schlegel HS (eds) The prokaryotes. A handbook on habitats, isolation, and identification of bacteria, Vol 1. Springer-Verlag, Berlin, p 4-43

Schwalbach MS, Hewson I, Fuhrman JA (2004) Viral effects on bacterial community composition in marine plankton microcosms. Aquat Microb Ecol 34:117-127

Sheldon RW, Prakash A, Sutcliffe WH Jr (1972) The size distribution of particles in the ocean. Limnol Oceanogr 17: $327-340$

Sherr E, Sherr B (2000) Marine microbes: an overview. In: Kirchman DL (ed) Microbial ecology of the oceans. WileyLiss, New York, p 13-46

Singh BK, Chattopadhyay J, Sinha S (2004) The role of virus infection in a simple phytoplankton-zooplankton system. J Theor Biol 231:153-166

Smith HL, Waltman P (1995) The theory of the chemostat: dynamics of microbial competition, Cambridge University Press, New York

Sterner R, Elser JJ (2002) Ecological stoichiometry: the biology of elements from molecules to the biosphere. Princeton University Press, Princeton, NJ

Suttle CA, Chen F (1992) Mechanisms and rates of decay of marine viruses in seawater. Appl Environ Microbiol 58: 3721-3729

Thingstad TF (2000) Elements of a theory for the mechanisms controlling abundance, diversity, and biogeochemical role of lytic bacterial viruses in aquatic systems. Limnol Oceanogr 45:1320-1328

Thingstad TF, Lignell R (1997) Theoretical models for the control of bacterial growth rate, abundance, diversity and carbon demand. Aquat Microb Ecol 13:19-27

Thingstad TF, Havskum H, Garde K, Riemann B (1996) On the strategy of 'eating your competitor'. A mathematical analysis of algal mixotrophy. Ecology 77:2108-2118

Thingstad TF, Bratbak G, Heldal M, Dundas I (1997) Trophic interactions controlling the diversity in pelagic microbial food webs. In: Martins MT, Sato MIZ, Tiedje JM, Hagler LCN, Dobereiner J, Sanchez PS (eds) Progress in microbial ecology. Brazilian Society for Microbiology (SBM)/ International Committee on Microbial Ecology (ICOME), Sao Paulo, p 107-114

Venter JC, Remington K, Heidelberg JF, Halpern AL and 19 others (2004) Environmental genome shotgun sequencing of the Sargasso Sea. Science 304:66-74

Weinbauer MG, Rassoulzadegan F (2004) Are viruses driving microbial diversification and diversity? Environ Microbiol $6: 1-11$

Wichels A, Biel SS, Gelderblom HR, Brinkhoff T, Muyzer G, Schutt C (1998) Bacteriophage diversity in the North Sea. Appl Environ Microbiol 64:4128-4133

Winter C, Smit A, Herndl GJ, Weinbauer MG (2004) Impact of virioplankton on archaeal and bacterial community richness as assessed in seawater batch cultures. Appl Environ Microbiol 70:804-813 
Appendix 1. How to calculate the equilibrium of the system

Here, we explain how we obtained the equilibrium $E_{n}$, in which $(n-1)$ pairs of host and virus, $n$th virus-free host, and protozoa coexist with assumption of no immigration. We consider the potential equilibrium $E_{s}$ in which only $(s-1)$ pairs of host and virus, $s$ th virus-free host, and protozoa coexist, where $s \geq 1$. At $E_{s}$, when the predicted abundance of $s$ th virus-free bacteria, $U_{s, s}{ }^{*}$, is larger than the abundance of virus-associated bacteria $U_{s}{ }^{* *}\left(=U_{1, s}{ }^{*}=\right.$ $\left.U_{2, s}{ }^{*}=\ldots U_{s-1, s^{*}}\right)$, we can consider $s$ th virus are also able to establish populations, and we can then judge that potential equilibrium $E_{s}$ is not at equilibrium. We then proceed to the next equilibrium $E_{s+1}$, and iterate this until the inequality $U_{S, S}{ }^{*}<U_{S}{ }^{* *}$ holds. The smallest $s$ that satisfies the above inequality is the realized species number $n$ at equilibrium $\left(n^{*}\right)$.

From Eqs. (1) to (5), we calculate each component at the potential equilibrium $E_{s}$. From $\mathrm{d} P / \mathrm{d} t=0$ (in Eq. 4 ), the total abundance of uninfected and infected bacterial cells, and viruses should satisfy the following equation:

$$
\begin{aligned}
& \alpha_{P U} \rho_{B} \sum_{j=1}^{j=s} U_{j, s}{ }^{*}+\alpha_{P I}\left(\rho_{B}+n_{V} \rho_{V}\right) \sum_{j=1}^{j=s-1} I_{j, s}{ }^{*}+ \\
& \alpha_{P V} \rho_{V} \sum_{j=1}^{j=s-1} V_{j, s}{ }^{*}=Y_{P}{ }^{-1} \rho_{P}\left(\delta_{P}+D\right)
\end{aligned}
$$

From $\mathrm{d} I_{j} / \mathrm{d} t=0$ (in Eq. 2), we obtain the density of infected cells of the $j$ th species:

$$
I_{j, s}{ }^{*}=\frac{L \beta V_{j, s}{ }^{*} U_{j, s}{ }^{*}}{1+D L+\alpha_{P I} L P_{s}{ }^{*}} \quad(j=1,2, \ldots, \mathrm{s}-1)
$$

Substituting Eq. (A2) into $\mathrm{d} V_{j} / \mathrm{d} t=0$ (in Eq. 3), assuming $V_{j, s}{ }^{*}>0$, and rearranging it, we obtain:

$$
\begin{gathered}
U_{j, s}{ }^{*}=\frac{\left(1+D L+\alpha_{P I} L P_{s}{ }^{*}\right)\left(\lambda+D+\alpha_{P V} P_{s}{ }^{*}\right)}{\beta\left[n_{V}\left(Y_{V}-1-D L\right)+Y_{V} \rho_{B} \rho_{V}{ }^{-1}-n_{V} \alpha_{P I} L P_{s}{ }^{*}\right]}\left(=U_{s}{ }^{* *}\right) \\
(j=1,2, \ldots, s-1)
\end{gathered}
$$

From $\mathrm{d} U_{s} / \mathrm{d} t=0$ with $V_{s, S}=0$, we obtain the density of protozoa:

$$
P_{S}^{*}=\alpha_{P U}{ }^{-1}\left(Y_{B} \rho_{B}{ }^{-1} \alpha_{s} N_{s}^{*}-D\right)
$$

Using Eq. (A4) and $\mathrm{d} U_{j} / \mathrm{d} t=0$ (in Eq. 1), we obtain the density of viruses:

$$
V_{j, s}{ }^{*}=\beta^{-1} Y_{B} \rho_{B}^{-1}\left(\alpha_{j}-\alpha_{s}\right) N_{s}^{*}
$$

Substituting Eqs. (A2) \& (A5) into Eq. (A1), we can calculate the density of the $s$ th bacteria:

$$
\begin{aligned}
U_{s, s}{ }^{*} & =\alpha_{P U}{ }^{-1} \rho_{B}{ }^{-1} Y_{P}{ }^{-1} \rho_{P}\left(\delta_{P}+D\right)-(s-1) U_{s}^{* *} \\
& -\frac{L \alpha_{P U}{ }^{-1} \alpha_{P I} \rho_{B}{ }^{-1} Y_{B}{ }^{-1}\left(1+n_{V} \rho_{B}{ }^{-1} \rho_{V}\right)}{1+D L+L \alpha_{P I} P_{s}^{*}}\left\{\sum_{j=1}^{s-1} \alpha_{j}-(s-1) \alpha_{s}\right\} N_{s}^{*} U_{s}^{* *} \\
& -\alpha_{P V} \alpha_{P U}{ }^{-1} \beta^{-1} Y_{B} \rho_{V} \rho_{B}{ }^{-1}\left\{\sum_{j=1}^{s-1} \alpha_{j}-(s-1) \alpha_{s}\right\} N_{s}^{*}
\end{aligned}
$$

Using Eqs. (1) to (6), we can find that the dynamics of total nutrient $T_{N}$ is given by Eq. (7). This is calculated from the following equation:

$$
\begin{aligned}
& \mathrm{d} T_{N} / \mathrm{d} t=\mathrm{d} N / \mathrm{d} t+\sum_{j=1}^{j=m} \rho_{B} \mathrm{~d} U_{j} / \mathrm{d} t+ \\
& \sum_{j=1}^{j=m}\left(\rho_{B}+n_{V} \rho_{V}\right) \mathrm{d} I_{j} / \mathrm{d} t+\sum_{j=1}^{j=m} \rho_{V} \mathrm{~d} V_{j} / \mathrm{d} t+\rho_{P} \mathrm{~d} P / \mathrm{d} t
\end{aligned}
$$

Therefore, from $\mathrm{d} T_{N} / \mathrm{d} t=0$, the following equation should be satisfied at equilibrium with no immigration:

$$
\begin{aligned}
& s_{N} / D=N_{s}{ }^{*}+\sum_{j=1}^{j=s} \rho_{B} U_{j, s}{ }^{*}+ \\
& \sum_{j=1}^{j=s}\left(\rho_{B}+n_{V} \rho_{V}\right) I_{j, s}{ }^{*}+\sum_{j=1}^{j=s-1} \rho_{V} V_{j, s}{ }^{*}+\rho_{P} P^{*}
\end{aligned}
$$

By substituting Eqs. (A2) to (A6) into Eq. (A8) and rearranging it, we can obtain a quadratic equation of $N_{s}{ }^{*}$ (not shown here). By solving this equation and using the solution $N_{s}{ }^{*}$, we can check the inequality $U_{s, s}{ }^{*}<U_{s}{ }^{* *}$. By iterating these calculations numerically, we obtain the BSR $n$ at equilibrium $n^{*}$.

Appendix 2. How to derive the model of pure KW process

The equilibrium of our KKW model converges to the equilibrium of the model of pure KW process when the latent period $L \rightarrow 0$. The corresponding pure KW process model consists of Eq. (1) for the dynamics of bacterial cells, Eq. (4) for the dynamics of protozoa, and Eq. (5) for nutrients by setting $I_{j}=0$, and the following equation for the dynamics of free-living viruses, instead of the original Eq. (3):

$$
\mathrm{d} V_{j} / \mathrm{d} t=\left[Y_{V}\left(\rho_{B} \rho_{V}^{-1}+n_{V}\right)-n_{V}\right] \beta V_{j} U_{j}-\alpha_{P V} V_{j} P-\lambda V_{j}-D V_{j}
$$

This equation is obtained by substituting the following equation from $\mathrm{d} I_{j} / \mathrm{d} t=0.0$ into Eq. (3):

$$
I_{j}=\frac{L \beta V_{j} U_{j}}{1+D L+\alpha_{P I} L P}
$$

Then, by solving $\mathrm{d} U_{j} / \mathrm{d} t=0, \mathrm{~d} V_{j} / \mathrm{d} t=0$, and $\mathrm{d} P / \mathrm{d} t=0$, we can calculate the equilibrium of the pure KW process model. Note that calculations at equilibrium are eventually identical to the calculations in the KKW model with $L=0$ and $\alpha_{P V}=0$ (Appendix 1), although temporal dynamics of the 2 models are of course different. Therefore, we are able to discuss both pure KW process and KKW models at equilibrium 